\title{
Primum non nocere when the treatment is worse than the disease
}

\author{
James Jaggers, MD
}

\footnotetext{
From the Department of Cardiac Surgery, University of Colorado Section of Congenital Cardiac Surgery, Children's Hospital of Colorado, Aurora, Colo

Disclosures: Author has nothing to disclose with regard to commercial support.

Received for publication Dec 19, 2017; accepted for publication Dec 20, 2017; available ahead of print Feb 1, 2018.

Address for reprints: James Jaggers, MD, Department of Cardiac Surgery, University of Colorado Section of Congenital Cardiac Surgery, Children's Hospital of Colorado, 13123 East 16th Ave, B200, Aurora, CO 80045 (E-mail: James.Jaggers@childrenscolorado.org).

J Thorac Cardiovasc Surg 2018;155:1769-70

$0022-5223 / \$ 36.00$

Copyright (c) 2018 by The American Association for Thoracic Surgery

https://doi.org/10.1016/j.jtcvs.2017.12.106
}

We most commonly attribute this precept, originally written as "to abstain from doing harm," to the Hippocratic oath. "First do no harm" is one of the most basic tenets of clinical and research ethics and is central to modern Western medicine. This precept is at the heart of the debate concerning treatment for anomalous aortic origin of a coronary artery (AAOCA). In an effort to treat or prevent the risk of potentially devastating cardiac events in children and young adults, we have often erred on the side of more aggressive therapy in asymptomatic or questionably symptomatic patients, even in the face of minimal risk of cardiac ischemia and sudden cardiac death. Surgery has been justified on the basis of the low risk of the surgical intervention and because consensus-based guidelines, until recently, have recommended avoidance of competitive athletic activity for all patients with AAOCA unless a successful surgical procedure was performed. When parents are faced with the decision to limit the exercise of their athletic, asymptomatic child or to have a "low-risk" surgical procedure to treat the AAORCA, they invariably choose a procedure, believing that the surgery will alleviate risk and allow their child to pursue dreams of competitive sports. It has only been the last 2 years that these consensus-based guidelines have adopted a more conservative course. In the most recent consensus statement, ${ }^{1,2}$ recommendations for asymptomatic patients without evidence of ischemia by provocative testing and careful clinical history are that they may participate in competitive sports after proper counseling.

These guidelines are intended to be a foundation of knowledge for which to base individual clinical decisions, but they are based on some important assumptions that may overestimate or underestimate the risks. We must remember that consensus-based guidelines do not take the place of sound clinical judgment.

Once the decision to perform surgery has been made, several surgical procedures have been described. Most procedures are designed to address the potential mechanisms

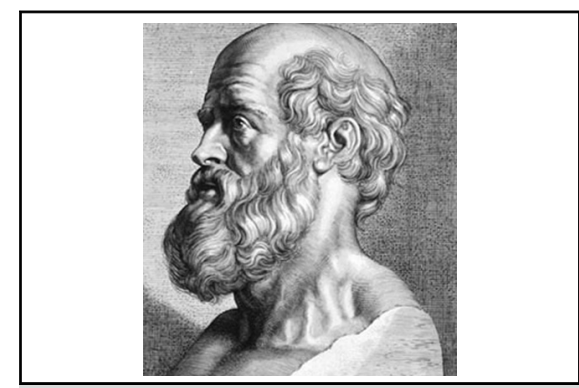

Greek physician Hippocrates (460 BC to 370 BC), author of the oath.

\section{Central Message}

Surgical therapy for AAOCA is safe, but the effectiveness of surgical therapy and the appropriate selection of patients who may benefit from intervention remain in question.

See Article page 1760 .

for ischemia. But none of these procedures have been compared in a meaningful manner, so the superiority of any one remains speculative.

We must not forget the importance of the technical details of the operations. In AAORCA, the intramural segment may be short, so that a simple unroofing may leave a segment of coronary between the aorta and the pulmonary artery and with a persistent oblique angle of departure from the aorta. These are 2 of the important mechanisms for potential ischemia, and a simple unroofing may leave the surgeon and patient with uncertainty of the effectiveness of the procedure. In this situation, it may be better to perform a translocation procedure to completely address all of the potential mechanisms of ischemia. Of course, this increases the technical complexity of the procedure, and other potential pitfalls come into play. Also, the intramural coronary artery and proximal segment are often smaller and irregular in appearance. Perhaps we are leaving diseased or stenotic coronary artery behind.

In this study, ${ }^{3}$ all patients received an unroofing procedure. Perhaps some of the factors listed may be relevant, and a simple unroofing may not completely address the pathology.

Immediately after the surgical intervention in the operating room, we can only infer success of the operation by a combination of normal right ventricular function, normal electrocardiogram, and patency of the operated coronary. This is objectively unsatisfying. 
Even when we have done what we think is a bang-up surgery, we still do not have data to determine the unnatural history of the operated unroofed or translocated and reimplanted coronary artery.

The most important finding of this study is that more than half of the operated patients had new or persistent symptoms after what was thought to be a successful intervention. Nine of these patients were asymptomatic before surgery. This is consistent with other reports that demonstrate symptoms and perfusion defects after repair of AAORCA,${ }^{4}$ but inconsistent with other reports in which a small number of symptomatic patients after repair had widely patent coronary arteries and no evidence of functional ischemia after surgery despite the presence of symptoms. ${ }^{5}$ So it appears that patency of the coronary artery, negative stress testing, and normal electrocardiogram do not adequately predict a successful operation as measured by relief of symptoms.

This study has important limitations that are consistent with the retrospective nature and short-term follow-up. Twenty percent of the patients were lost to follow-up. There was a nonstandardized preoperative and postoperative management. The approach to diagnosis and confirmation was not standard and varied significantly, especially in the patients with new or persistent ischemic symptoms. Despite these limitations, the implications of this article are that we may not be accomplishing what we think we are with our surgical intervention. Ultimately, we have to correctly identify the patients who will benefit from an operation. Registries will help us understand the current state of therapy and the outcomes of our interventions, but until we have better understanding of the unoperated patients or the denominator and have a functional test that can predict and characterize ischemia better, we may still be violating Primum non nocere.

\section{References}

1. Brothers JA, Frommelt MA, Jaquiss RDB, Myerburg RJ, Fraser CD Jr, Tweddell JS. Expert consensus guidelines: anomalous aortic origin of a coronary artery. J Thorac Cardiovasc Surg. 2017;153:1440-57.

2. Van Hare GF, Ackerman MJ, Evangelista JA, Kovacs RJ, Myerburg RJ, Shafer KM, et al. Eligibility and disqualification recommendations for competitive athletes with cardiovascular abnormalities: Task Force 4: Congenital heart disease: A scientific statement from the American Heart Association and American College of Cardiology. Circulation. 2015;132:e281-91.

3. Sachdeva S, Frommelt MA, Mitchell ME, Tweddell JS, Frommelt PC. Surgical unroofing of intramural anomalous aortic origin of a coronary artery in pediatric patients: Single-center perspective. J Thorac Cardiovasc Surg. 2018; 155:1760-70.

4. Brothers JA, McBride MG, Seliem MA, Marino BS, Tomlinson RS, Pampaloni MH, et al. Evaluation of myocardial ischemia after surgical repair of anomalous aortic origin of a coronary artery in a series of pediatric patients. $J$ Am Coll Cardiol. 2007;50:2078-82.

5. Turner I, Turek JW, Jaggers J, Herlong JR, Lawson DS, Lodge AJ. Anomalous aortic origin of a coronary artery: preoperative diagnosis and surgical planning. World J Pediatr Congenit Heart Surg. 2011;2:340-5. 